\title{
El voluntariado universitario como compromiso con la sociedad
}

\section{University volunteering as a commitment to society}

Andrés Alberto Chávez Eras

Universidad Internacional del Ecuador, Ecuador

María de los Ángeles Molina Velásquez

Universidad Internacional del Ecuador, Ecuador

Autor para correspondencia: anchavezer@internacional.edu.ec

Fecha de recepción: 25 de Enero de 2017 - Fecha de aceptación: 25 de Marzo de 2017

\section{Resumen}

Este articulo hace énfasis a los dos puntos principales al momento de iniciar una carrera profesional en la universidad, la primera es formarse como personas competitivas en el medio que se escogió para ejercer, la segunda que va con nuestra educación desde niños que es ser personas integras y comprometidas al desarrollo y necesidades de la sociedad, muchas veces ese servicio puede venir desde la carrera que tomamos, esta puede servir directa o indirectamente a los demás, lo importante es estar predispuestos a contribuir para pequeñas mejoras de nuestro entorno. Por lo cual se analizaran temas relacionados a la vinculación que se da a nivel académico.

Palabras claves: Labor social; voluntariados; universitarios; profesional

\begin{abstract}
This article emphasizes the two main points when starting a professional career in the university, the first is to form as competitive people in the middle that was chosen to perform, the second that goes with our education since children is to be people integrated and committed to the development needs of society, and many times that service can come from the career we take, it can serve directly or indirectly to others, the important thing is to be predisposed to contribute in our society. Therefore, we will analyze issues related to the linkage that occurs at the academic level.
\end{abstract}

Key words: Social work; volunteers; university students; professionals 


\section{Introducción}

¿Porque pensamos realmente en ayudar a un desconocido? ¿Qué hay tras las emociones y necesidades de ambas partes en los programas de voluntariado? ¿Sera acaso empatía, valores, religión, compasión? o simplemente es la necesidad de contribuir con un granito de arena a construir una sociedad mejor.

"Los voluntarios son los únicos seres humanos sobre la faz de la tierra, que reflejan la compasión de esta nación, el cuidado desinteresado, la paciencia, y el amor puro de unos a otros" (Bombeck, 1987).

El voluntariado comprende todas las actividades que son de beneficio mundial, llevadas a cabo por personas que no esperen ningún tipo de remuneración o compensación alguna, misma que se debe dar de manera consciente y con un ánimo generoso, simplemente que nazca con la idea de utilizar nuestras vidas para ayudar a mejorar la calidad de vida de los demás.

Hoy en día los universitarios se preparan en áreas como matemáticas y ciencias, pero un verdadero profesional no es competente únicamente en el sentido cognitivo sino deben ser capaces de tener una integración social con su medio, permitiendo utilizar algo de lo aprendido académicamente para beneficio y mejoras del nivel de vida de la sociedad. Si bien es un requisito de graduación para los alumnos, se debe fomentar por parte de las autoridades a cargo un verdadero compromiso e involucramiento de todas las partes para desarrollar diversos programas.

El siguiente documento hablara del compromiso del voluntariado en las universidades, clasificándolo en el voluntariado como principio humanitario, programas de vinculación universitaria y voluntariado acorde al perfil de los estudiantes.

\section{El voluntariado como principio humanitario}

¿Qué aspecto tiene el amor? Tiene las manos para ayudar a otros. Tiene los pies para apresurarse a los pobres y a los necesitados. Tiene ojos para ver la miseria y la necesidad. Tiene oídos para oír los suspiros y las tristezas de los hombres. Así es la apariencia del amor" San Agustín (Hipona, Del 386 al 419)

Si hacemos memoria sobre el tiempo desde que cierta cantidad de personas ayudan a otras en diferentes aspectos para que lleguen a mejorar su calidad de vida, tal vez sea desde siempre, desde que cada uno de nosotros hemos crecido independientemente de la generación siempre ha habido personas caritativas, desde personas reconocidas como Madre Teresa de Calcuta, el Papa, hasta muchas personas anónimas que siempre han estado dispuestas a dar lo mejor de sí sin ningún interés. Pero si nos vamos aun a tiempos más atrás, desde los primeros hombres en la tierra y tiempos a.C se llevaba a cabo quizás de una manera independiente aunque no tenía un nombre en específico como "voluntario". (López, 1991)

A fin de cuentas en los tiempos que sean la labor social es un acto de amor concreto, y se podría decir que el precedente más grande de amor desinteresado a los otros es el de Jesús, él fue 
quien creo este ejemplo más grande, que no solo basto con ayudarnos, y hacer milagros, sino que hasta dio su vida por cada uno de nosotros independientemente de si nosotros le agradeceríamos o fuéramos recíprocos, simplemente fue por amor "estrechándonos contra su corazón". Con este ejemplo tan sagrado y valioso lo único que nos queda es tratar de imitar la actitud de Jesús, que aunque nosotros no somos capaces de sacrificios tan grandes, si podemos empezar con pequeñas contribuciones y siempre siguiendo ese ejemplo. (Greeley, 2000, pág. 42)

Este tipo de prácticas aparentemente son sencillas, pero no es así realmente no todos sienten la empatía por los demás, y más aún en estos tiempos que cada cual se interesa únicamente por su beneficio. En muchos de los casos de las personas que han iniciado actividades como voluntarios se dieron inculcadas por sus padres, otros desde niños, o inclusive este amor nació desde las instituciones educativas, pero independientemente de donde surgió la iniciativa este tipo de ayudas en realidad es considerado un don, que nos permite no portarnos indiferentes ante la constante necesidad que vivimos en nuestro alrededor, es un perfil único porque no se espera ninguna garantía de vuelta. (Bejar, 2006, pág. 104)

En la mayoría de los casos de las personas que no sienten el compromiso o empatía con los casos que ven a diario el limitarse con etiquetarlos como "pobrecitos" sean ancianos, discapacitados, aquellos que sufren abusos o enfermedades o cualquier otro tipo de situaciones, viven afligidos por esos difíciles escenarios que le toca pasar en su diario vivir, ¿nos hemos puesto a pensar acaso porque ellos y no nosotros? ¿Suerte? ¿Trabajo más duro?, en realidad nadie sabe, pero lo que sí es seguro es que todo en esta vida pasa por algo y ni ellos ni nosotros ganaremos absolutamente nada con quejas, lagrimas o únicamente sintiendo lastima por el otro, que durara únicamente mientras lees, ves o te cuenten alguna noticia, considero que el verdadero compromiso inicia con sentir una verdadera compasión a la humanidad, eso te llevara poco a poco a un sentimiento de empatía profunda y así a una responsabilidad mucho mayor por los demás. (Mendez, 2009)

La "teoría de los sentimientos morales" nos ayuda a esclarecer un poco más esta idea de no hacernos de ojos ciegos, ni de oídos sordos sino comprender la importancia del mecanismo de la empatía y relacionándolo como un "cambio imaginario" que implica comprender sinceramente las condiciones del prójimo. (Smith, 2004, pág. 105)

\section{Programas de vinculación universitaria}

Los programas de vinculación en las universidades son más eficaces de lo que creemos, podemos implementar actividades que contribuirán así a cambios positivos. La ayuda en muchas ocasiones nos limita a pensar que se puede dar solo de carácter económico, y si no tengo dinero no puedo ayudar eso es muy erróneo, la ayuda también puede darse donando alimentos o vestimenta. Se puede ayudar de tantas maneras como impartiendo los conocimientos que has adquirido en la universidad, en charlas o capacitaciones, inclusive lograr distraerlos con cualquier actividad entregando un poco de nuestro tiempo, o simplemente mostrándoles apoyo con un abrazo o palabras de aliento (Karylowski, 1982).

Se puede ayudar en mejoras económicas creando fondos con programas de micro emprendimiento, también en aprendizaje impartiendo todo el conocimiento recibido por parte de 
los profesores, se podrán transmitir a personas para reducir índices de analfabetismo y sean personas con más conocimiento y criterios como para emprender en diferentes aspectos de sus vidas, sea en lo personal o laboral. (Funes, 1995)

Uno de los puntos más válidos y aplicados en las instituciones educativas es contribuir con el aprendizaje, es decir esos conocimientos adquiridos en las aulas por parte de los estudiantes entregarlos a las personas, previamente se podrá realizar un análisis de sectores, temas de interés y necesidades del mismo. Y así ya conociendo realmente que es lo que se necesita se empiezan los programas para ayudar a aportar con el emprendimiento y confianza de la comunidad. "De por sí se dice que el crecimiento constante de la moral de las personas está directamente vinculado con el desarrollo de competencias sociales y emocionales por tal el comportamiento pro social es un comportamiento altruista, justo, compartido o generalmente empático”. (Eisenberg, 1992, pág. 85)

Las competencias sociales de las que hablamos se pueden ir desarrollando desde diferentes vías como comunicación, desarrollo moral y tener un cierto grado de responsabilidad por la sociedad. (Martínez, Convivencia escolar: problemas y soluciones, 2001, pág. 86)

En la actualidad tanto en educación secundaria como universitaria es un requisito de graduación realizar vinculación con la comunidad, dependiendo la institución se determinara el número de horas a alcanzar y la actividad con la comunidad a realizar, se puede plantear 5 dimensiones para que los estudiantes mejoren estas competencias y se comprometa a todo el equipo de trabajo. (García, 1998, pág. 86)

1. Empatía

2. Asertividad

3. Autoestima

4. Comunicación

5. Desarrollo de la moral

Con los puntos mencionados se busca que ambas partes logren el equilibrio entre lo cognitivo y lo afectivo para un desarrollo más completo de sus capacidades para ser mucho más competentes en el entorno. (Tello, 2005) "Involucrando a su vez las competencias interpersonales tales como la empatía, influencia, resolución de conflictos, comunión" (Martinez, Temas de nuestro tiempo; psicología, educación, sociedad y calidad de vida, 1999, pág. 86)

\section{Tipos de voluntariado acorde al perfil de los estudiantes}

Dicen que cada cabeza es un mundo y efectivamente es así, y a la hora de hacer programas de voluntariado no podemos hacer una actividad que sea de gusto de todo el grupo, pero si se puede hacer que cada uno aporte de acuerdo a sus conocimientos, talentos y aptitudes, es decir que cada cual aporte con lo que sabe y le gusta fomentando un mayor compromiso con el programa. Nos encontramos en un mundo que está en un alto grado necesitado de ayuda por tantas causas, hay pobreza, desastres naturales, enfermedades, guerras en fin quizás nunca terminaríamos de enumerar las necesidades de todo el mundo, y el hecho de que tengamos algo de lo que le falta a alguien ya nos da un nivel de responsabilidad social, si ya mucho tiempo no 
se le ha dado la importancia ante tanta escasez nunca es tarde para extender nuestra mano solidaria. (Trianes., 1999)

En este proceso de investigación se encontraron 3 categorías de acuerdo a las capacidades del alumnado: (Vidal, Voluntariado y responsabilidad social en jóvenes estudiantes de educación superior, 2010, pág. 238)

- Voluntad libre: la labor que se realice en esta categoría se deberá dar sin ningún tipo de obligación deberá ser totalmente libre por parte de la persona.

Para este tipo de acciones se podrán hacer actividades independientes por parte de los estudiantes, ellos podrán plantear su programa de vinculación a la junta de alguna actividad que sea de su interés y contribuya positivamente a un sector, mismo que deberá estar respaldado con fotos, videos y supervisado por una autoridad de la institución.

- Motivación no pecuniaria: para el programa que se escoja no se deberá pensar en verse beneficiado de uno u otro modo, y menos aún esperar recibir algún tipo de paga Todos los gastos de surjan de transporte, alimentación, etc... durante el proceso, se deberá ver como una inversión a largo plazo, que será retribuida no de manera económica pero si con mejoras.

Para ello los alumnos de recursos limitados podrán hacer programas cercar de la institución educativa o sus hogares y que nos les genere gastos adicionales. Podrán realizar trabajos dependiendo las necesidades de ese sector.

- Beneficio para otros: En este caso lo que se busca es siempre favorecer a las personas o familias que se va a ayudar, las personas que están llevando a cabo el programa no deben pretender interés para ellos o su entorno social, no debe haber límite para los que reciban la ayuda se deberá buscar su bienestar ante todo. Aquí entran programas de voluntariado independientes, no limitarse a cumplirlo como un requisito que me imponen y olvidarme de los demás, y solo pensar en ayudar a mi familia y amigos, la ayuda la necesitamos todos y continuar con fundaciones o programas independientes para los demás. (Silva \& Canuto, 2013)

\section{Recomendaciones}

Este articulo mostro puntos cotidianos de todos aquellos que comienzas sus procesos educativos, en el caso de universitarios donde el tiempo es mucho más medido y las preocupaciones abordan diariamente sus vidas, comprometerse con programas de ayuda social parece no ser algo de interés, por eso se recomienda:

a) Con el constante desarrollo de las destrezas cognitivas de los estudiantes en el ámbito académico, plantear también un cronograma de actividades por ciclo académico de programas de labor social desde las más sencillas, hasta aquellas que requieran un poco más de su tiempo, para así ir fomentando entusiasmo por el bienestar social.

b) Incluir en los planes de estudio mayor participación por parte de la institución en programas de mejora no solo en las actividades por la universidad, sino en eventos independientes que requieran ser atendidos. 
c) Realizar constantes investigaciones de las comunidades, para comprender y atender la complejidad de las necesidades que son la vida diaria de nuestra comunidad y así avanzar con el desarrollo de proyectos. (Mato, 2013)

\section{Conclusiones}

Indiscutiblemente no solo las universidades, sino todos los establecimientos tienen conciencia de responsabilidad social, ayudar a los necesitados, acudir con colaboraciones cuando se lo necesita y demás, pero el trabajo realmente debe ser diario, si nos llegáramos a preguntar realmente cuantas necesidades tiene nuestra gente, solo nos bastara con mirar a nuestro alrededor y ver cuanta carencia de abrigo, solidaridad, fe, justicia y un sinfín de sucesos más saldrían cada hora, minuto y segundo. Por eso el actuar es ya, está en las manos de cada uno de nosotros contribuir con actos pequeños que van apareciendo día a día, nunca la ayuda será poca ni mucho menos suficiente, simplemente se reduce a querer hacerlo de corazón. "En cada comunidad, hay trabajo por hacer. En cada nación, hay heridas que sanar. En cada corazón, está el poder para hacerlo" (Williamson)

\section{Bibliografía}

Bejar, H. (2006). Voluntariado: Compasión o autorrealización. Cali: Universidad del Valle.

Bombeck, E. (1987). Importance of Volunteers; So Long Volunteers. San Francisco, California: Hudnut.

Eisenberg, N. \&. (1992). La empatía y su desarrollo. Bilbao: Descleé de Brouwer.

Funes, M. J. (1995). La ilusión solidaria. Madrid: UNED.

García, M. M. (1998). Actitudes y Estrategias Cognitivas Sociales. Madrid: España: TEA Ediciones S.A.

Greeley, A. (2000). The Catholic Imagination. Los Ángeles: Universtity of California Press.

Hipona, A. d. (Del 386 al 419). La filosofía del amor en san Agustín. Tagaste.

Karylowski. (1982). two types of altruistic behavior: doing good to feel good or to make the other feel good. Nueva York: Academic Press.

Lima, N. M. (2013). La intención emprendedora delos estudiantes universitarios en diferentes sistemas educativos. Madrid: ECEDE.

López, A. (1991). Libertad y solidaridad. Barcelona: Planeta.

Martínez, O. (1999). Temas de nuestro tiempo; psicología, educación, sociedad y calidad de vida. Madrid: Fundamentos. 
Martínez, O. (2001). Convivencia escolar: problemas y soluciones. Revista Complutense de Educación.

Mato, D. (2013). Contribución de experiencias de vinculación social de las universidades. Sorocaba: Campinas.

Méndez, M. (2009). Voluntariado universitario, participación ciudadana y desarrollo. Ciudad de México: La sociedad.

Silva, Y., \& Canuto, M. C. (2013). Niveles de engagement y burnout en voluntarios universitarios. Boletín de Psicología No108.

Smith, A. (2004). Teoría de los sentimientos morales. México: Edición conmemorativa.

Tello, V. (2005). Competencia social en la escuela. Bases para desarrollar la competencia social en la escuela.

Trianes., M. M. (1999). Relaciones sociales y prevención de la inadaptación. Málaga: Aljibe.

Vidal, K. J. (2010). Voluntariado y responsabilidad social en jóvenes estudiantes de educación superior. Concepción, Chile: Revista Trayectorias, Vol. 12, №31.

Williamson, M. (s.f.). Everyday Grace: Having Hope, Finding Forgiveness. Houston, Texas USA. 